\title{
Student Indicator of Social Media Addiction That Lead to Conflict
}

\author{
Matang Matang ${ }^{1,}$, , Bunyamin Maftuh ${ }^{2}$, Elly Malihah ${ }^{3}$, Ilham Hudi ${ }^{4}$ \\ 1,2,3 Universitas Pendidikan Indonesia, Bandung, Indonesia \\ ${ }^{4}$ Universitas Muhammadiyah Riau, Pekanbaru, Indonesia \\ *Corresponding author. Email: matang@upi.edu
}

\begin{abstract}
Students are now known as the second generation digital native who is very familiar with social media. This generation was born and grew as social media became more established. Massive use in addition to generational characteristics, the COVID-19 pandemic has become an alternative to various purposes in using social media. Excessive use of social media can have an impact on social media addiction. Previous research has shown a lot to do with social media use and addiction to social media. This study uses literature review with a conceptual analysis approach from various sources. By disclosing indicators that can cause students to become addicted to social media. Social media addiction has an impact on personal and intra-personal conflicts. Disturbed sleep patterns, decreased academic achievement, depression, stress, anxiety, loneliness, and self-esteem are all conflict causes for social media addiction. This study opens a gap for further research to reveal the relationship between indicators of the causes of social media addiction with the role of parents, peer influence, and stakeholder policies in preventing social media addiction.
\end{abstract}

Keywords: Conflict, Indicators of Social Media Addiction, Social Media Addiction, Students

\section{INTRODUCTION}

Social media is an integral part of the second generation of digital natives [1] [2]. This generation was born and raised in the context of increasingly massive digital mobility with the internet and Wi-Fi available on mobile devices to computers [3]. Students are currently the second generation of digital natives born after 1990 . The second generation is marked by the use of laptops, netbooks, tablets, and smartphones as facilities for streaming various kinds of content and a number of information available (online) they can easily find out. The second generation of digital natives apart from using the internet a lot, additionally they had a greater wonderful mind-set toward the net than the primary technology. In the second generation of digital natives, social media was very popular than it was in the first generation. Previous studies has proven that social media is inseparable in scholar life [4].

The use of social media is taken into consideration to be one of the maximum not unusual place amongst university college students that could have an effect on their each day life. It affects student academic [5], student self-confidence, self-esteem, life satisfaction [6], has an impact on student morale and behavior [7], which in turn also has an impact on student health [8]. This impact is in line with the motive for its use. The motives for using social media are to socialize, meet new people, express themselves, become more popular, and for entertainment [9]. Other research have proven that using social media is aimed toward communication goals [10] [11], for political participation [12] [13], for learning purposes [14] [15]. All of these items can take place due to the fact social media permits anyone to percentage or trade information, ideas, photographs or movies in digital groups and networks [16]. It may be concluded that the smart use of social media has advantages in diverse fields. Vice versa, if immoderate use of social media can purpose troubles and losses.

Social media use is known to have various benefits, but overuse it can lead to addiction. Social media addiction problems can be linked to mood problems, emotional issues, as well as interpersonal and psychological problems [17]. Social media additionally 
has an effective correlation with depression amongst university students [18]. In different words, the better the

equated with risky alcohol use personality traits [19]. Have a sensitivity to appreciation, narcissism, difficulty understanding or expressing emotions, and an attitude of taking action without thinking about the consequences. The resulting impact will affect the decline in work performance in activities carried out in everyday life.

The emergence of social media addiction problems due to sofalizing behavior [20]. Sofalizing is the behavior of someone who prefers to interact online from home rather than going out to meet. This behavior is chosen because it can describe the ideal image of themselves [21]. This is done to attract the attention of other people and can also improve the mood. However, this can have a negative impact in addition to addiction as well as social burdens, jealousy and envious. On the other hand, the contributing factor is the development of FoMO, which is commonly called the fear of losing or worrying about missing the latest information [22] [23]. FoMO and social level will coincide with feelings of loneliness, anxiety, and depression which cause a person to be addicted to using social media.

The period of time and hours spent on social media is likewise an element in inflicting a person to end up hooked on social media [24]. Late night social media use affects sleep quality [25], it indirectly affects study time [26] [27]. The bad consequences of social media additions encompass sleep quality, psychosocial behavior, instructional performance, and circadian rhythms or herbal techniques associated with the 24-hour wake-sleep cycle. Adverse effects of using social media before bed which result in terrible sleep quality, behind schedule sleep time, quick sleep time, immoderate sunlight hours sleepiness, insomnia, and nightmares.

From the numerous heritage troubles formerly disclosed, this take a look at social media addiction and the accompanying conflicts. Social media addiction can be identified through indicators via signs that motive social media addiction. This study take a look at additionally attempts to show what conflicts can arise whilst college students are hooked on social media.

\section{THEORETICAL REVIEW}

\subsection{Social Media Addiction}

Social media is a time period that describes the various virtual structures that permit interaction, create relationships, and collaboration amongst individuals who use it [28]. With mobile devices and web-primarily based structures constructed on Web 2.0 technology. Social media lets in its use on the micro, meso and macro tiers to percentage content material together with images, text, audio, video and video games in addition to construct relationships among people and interact a much wider public [29]. For social media users it method socialization, complete freedom of expression, sources of information, selection making, entertainment, research, and interest-primarily interactions. extent of a student's additions to social media, the better the extent of depression. Social media addiction is

Defining social media may not be as easy as it is used because of the many intersecting opinions and concepts. Social media and its sister time period Web 2.0 are hard to define, as there may be little settlement approximately what they mean [30]. In its most effective terms, social media are terms regarding the numerous offerings that humans effortlessly use to have interaction with different humans online. This is exemplified whilst looking or commenting on YouTube videos, like updating Facebook buddies and analyzing a persons' blog, that means you've got used social media. Based on the expert opinion that has been explained previously, it may be concluded that social media as a means of socialization continues to experience development. Media functions as a medium for interaction and participation with personal, community groups, social institutions and government. Social media provides services to its users with a variety of available content.

The social media noted on this observe are immediately associated with famous structures inclusive of Facebook, Instagram, YouTube, Twitter, TikTok, and others. The devices used can be computers, laptops, netbooks, tablets and cellphones, especially smartphones. Each platform has a hard and fast of viable movements that may be taken with the aid of using people interacting with it. such as creating personal data profiles on social media, publishing content (text, photos, and / or videos), praising or react to content material (likes, favorites, etc.), share content, comment on content, create groups and send direct messages and chat with different users, hook up with different profiles (as friends, followers, etc.), and buy products and make transactions [31]. Each type of social media itself has different features as distinctive features from others such as a "like" site on Instagram which is different from the "like" feature on Facebook.

Every social media has an appeal for users to continue using it [32]. Such attractiveness leads to personal interest in, or support for, messages that open by clicking the "Like" or "Share" button [33]. Social media will certainly be an emotional attraction, continue to provide information, and there is creativity both from the platform and from its users who contribute to making social media continue to be attractive. However, immoderate use of social media will definitely bring about social media addiction [34] [35] [36] [37].

There is widespread disagreement over whether social media addiction is a serious problem. Some insist that the threat of internet addiction has been exaggerated [38]. They argue that it is normal to spend a lot of time online as the Internet is increasingly the center of communication, shopping, entertainment and many other aspects of life. However, several studies [39] caution that many people who spend large amounts of time online are actually doing it because they are addicted to it and argue that it is an increasingly common problem. Social media addiction can lead to physical problems, unhappiness, and personal problems [38]. Physical problems are when a person addicted to social media spends a lot of time 
online for hours in one position such as sitting at a computer or holding a smartphone or other device. So far, being in one position can cause various physical problems. The unhappiness when people addicted to social media don't experience popularity is like getting the most friend requests or getting the most photo tags. Social media addiction negatively influences one's private relationships and they neglect their relationships with friends and family. This will then end up a struggle for those who are hooked on social media.

\subsection{Conflict Due to Social Media}

Conflict is an inevitable aspect of the human condition [40]. Conflict can be a powerful source of communication as well as a source of greater selfawareness. For this reason, there will be no conflict if disputes can be resolved rationally, or logically. Conflict as a fact of human life can occur in relationships, family, work, or friends [41]. This occurs naturally in all types of environments. When people experience conflict, most of their energy is channeled into emotions and strategies related to the conflict. They may be scared, angry, upset, hopeless, busy, or stressed. In this situation the improvement of social media and the bad consequences of social media addiction also can cause conflict.

Conflict on social media and the outcomes of social media addiction turns into a conflict. Conflict on social media can occur due to information conflicts [42]. Information-based social media conflicts can become a potential disruption in information warfare. Social media has also changed the way teenagers experience conflict. Social media capabilities growth on-line war into offline fights in adolescents [43]. Social media capabilities inclusive of photos, comments, stay streaming movies are locations of on-line war. The function of the capabilities that shape interpersonal conflicts. An enormous supply of preventing on social media will growth the probability of offline violence.

In addition to social mediation, it can lead to conflicts among users or interpersonal conflicts [44]. Social media addiction can also lead to conflict between children and parents [45], on a group scale or online community [46] social media is intensively used to frame conflict. The popularity of social media creates conflicts between children and parents. The emergence of social media with the fear of parents forms a source of conflict between parents of teenagers. Conflict due to social media use revolves around children's interactions with the opposite sex, and depression. The battle additionally indicates that social media and relationship are famous with teenagers, however that the older era isn't always supportive of them.

Previous studies has recognized one terrible effect of social media as technostress [47]. This refers back to the strain resulting from social media as ailment which in flip can result in technostress and net addiction. There are four frameworks for understanding the have an effect on of social media on conflict, specifically social media lowering the intensity of a communication, the speed and dissemination of information, adaptation to changes in communication technology, and data provided by social media is not only an important resource but also fundamentally changes information to shape the conflict. himself [48]. Social media and the results of social media addiction will truely result in a conflict, be it interpersonal conflicts, conflicts between children and parents, and conflicts between users, both individuals and community groups.

\section{METHOD}

This study used a literature review [49] [50] [51] with a conceptual analysis approach from various sources related to indicators of social media addiction and the accompanying conflicts. To compile studies, we conducted searches on the ScienceDirect, Taylor \& Francis Online databases, SAGE Journals, ERIC Institute of Education Eciences, and generally the google scholar database. In addition, data is also obtained from books, sources from websites, and others.

With the keyword "social media addiction" on google scholar, articles selected from 2015 to 2020 found 478 articles which were then used in the VOSviewer application known to be addicted to social media on four scales, consider Fig. 1. Cluster 1 social media addiction related to information, life, social media usage, social media network, time, and way. Cluster 2 social media addiction is related to college student, fear, fomo, present study, and smartphone addiction. Cluster 3 social media addiction related to Facebook, influence, Instagram, and youth. Cluster 4 social media addiction related to internet addiction, life satisfaction, loneliness, and relations.

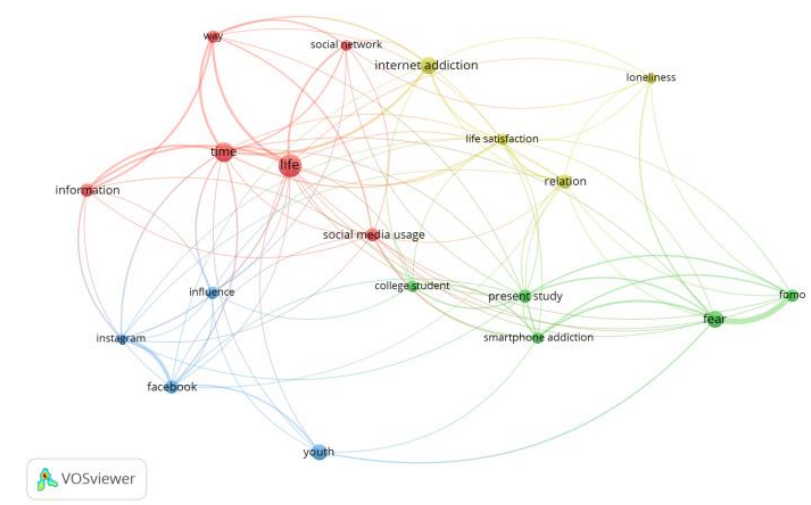

Figure 1. Data with the keywords "social media addiction" VOSviewer 


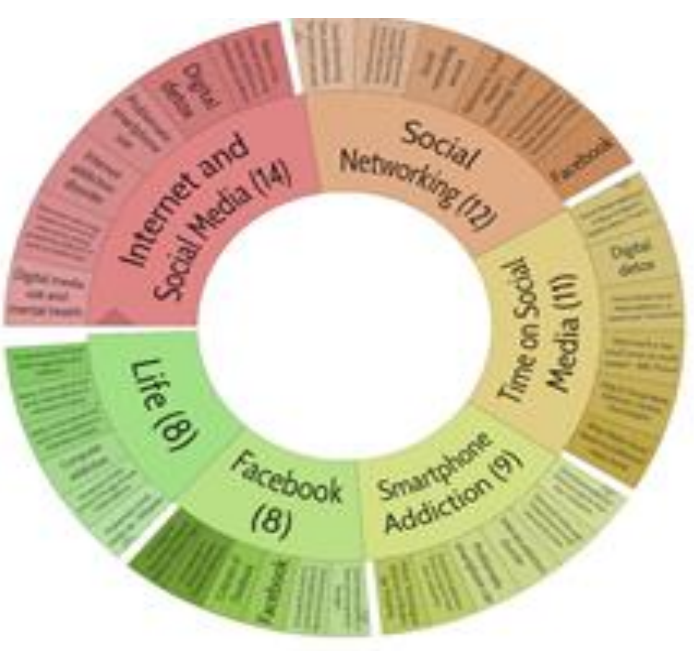

Figure 2. Data with keywords "social media addiction" search.carrot2.org

A search was also carried out on the web search.carrot2.org with the keyword "social media addiction", see Fig. 2. It is known that there are six keyword components related to social media addiction. Consisting of social networking, internet and social media, smartphone addiction, time on social media, facebook, and life. Of these components, there are several keywords that are scattered in each section including technology addiction, drug addiction, mental disorder, computer, overuse, treatment, university students, video game addiction, according to a study, examine the relationship, governments, digital detox, feel , food addiction, lessons learned, model of addiction, fear of missing, internet addiction is increasing in college students, obsessive, and ongoing covid-19 pandemic is likely to enhance.

\section{RESULTS AND DISCUSSION}

In measuring whether people or students are addicted to social media, it can be seen from various indicators that cause it. In a study [52] indicators of social media addiction, specifically do you spend a number of time considering social media or do you propose to apply it? Do you sense the want to apply social media extra regularly? Have you ever used social media to degree your private problems? Have you attempted to prevent the use of social media and failed? Do you sense demanding or uneasy in case you are prohibited from the use of social media? Do you operate social media so often that its use has a negative impact on your studies or work? In this look at the emphasis may be on signs of social media on the time of use. From the time of use how regularly the time is used for social media, feeling anxious and uneasy if it is prohibited to use it. Frequent use will cause private conflicts so you consider quitting, due to the fact addicted to social media has a poor effect on studies and work. Research [53] diagnosed similarities and variations in character traits of humans hooked on social media with traits, self-esteem, and positive self. The indicators of social media addiction are presented; how regularly do you check your social media accounts?, how regularly do you submit updates or different records on your social media accounts?, about how many friends do you have on your social media accounts?, how many hours a day do you log into the Internet on a day work and weekends?, and wherein do you sense extra able to being the actual you? There are questions that are relatively the same as when to use it, but this indicator is more of a self-disclosure of someone who is addicted to social media.

Research [54] specifically presents an indicator of addiction in in phrases of time spent. The signs are no way use social media, I use it once a month, once a week, every day, and the variety in their social media followers. Research [55] indicates predictors of social media addiction. Consists of fear of missing out (FOMO), compulsive use, attention deficit, self-esteem, loneliness, impulsivity, narcissism, personality traits, life satisfaction, depression, and empathy. FOMO is defined as the fear of missing out on information. FOMO right here has an instantaneous involvement in social media addiction. Overuse conduct is likewise diagnosed with inside the idea of complicated conflict. Narcissism is definitely associated with social media addiction because of getting rewards with inside the shape of "likes" and fantastic remarks from followers. Conflict also can be visible with inside the lifestyles pride of folks who are hooked on social media which leads to depression.

Behavioral signs of social media addiction [56] propose obsessive or compulsive conduct. Spending a whole lot of time considering social media or making plans a way to use it. Feeling preoccupied with the usage of social media can bring about over-sharing. Oversharing begins offevolved with pronouncing an excessive amount of after which regretting what we said. Those who be afflicted by addictions do now no longer continually choose what's suitable or beside the point to publish due to their preoccupation with checking and responding, which results in consistent involvement with inside the activity. Feeling the urge to frequently use social. In different words, the default preference for your free time activities is on social media. Even while you're out with a friend, you log into the social media app on your smartphone occasionally throughout short moments without interaction. Using social media to forget personal problems. One element of addiction is the capacity to apply the behavior as a psychological escape from problems. A person may have relationship problems and an social media is a comfortable way to temporarily calm the underlying stress caused by the problem. The use of social media then will become a distraction from the trouble due to the fact one's interest is continually diverted with the aid of using its use. Become anxious or afflicted if using social media is prohibited. When talking about social media addiction, begin feeling anxious if you can't access social media or feel pressured when forced to leave without access to media. Too frequently use social media in order that it will become a supply of conflict having a poor effect on relationships. When users are accustomed to communicating on social media through messaging, posts, sharing, commenting on, and "liking", they'll experience extra snug socializing on-line than offline. The conduct will become dangerous so the user will become uncomfortable or fearful of face-to-face 
communication, which is a much richer experience than communicating online where one cannot actually see non-verbal communication such as in gestures, body language and tone sound.

\section{CONCLUSION}

In general, indicators of social media addiction are associated with to the time you use social media, the longer you use social media, the more users can be identified as addicted to social media. The development of the usage time scale question will be related to how many hours are spent in a day using social media? From the time of use will be related to how many days a week do not use social media? How many months of the year do you not use social media? The next indicator feels that they want to continue using social media and are afraid to miss out on information from social media. Social media is the most important thing in addicted users' lives. The closeness of users to social media is also an indicator if they are prohibited from using or leaving social media. The no-use indicator will have an impact on users who are sad, even depressed. Indicators of social media use occur health, academic problems as well as relationships with girlfriends, friends, and family.

Indicators of social media addiction are always associated with users. It should be a check if indicators of social media addiction are directed at social media itself. Algorithms in social media technology cannot be denied that people continue to use social media [31] [57] [58]. Psychoanalysis of social media users which will be seen in the role of algorithms in the process of using media. Algorithms in general are more than just watching, viewing, doing, participating, using, communicating, giving and interacting. As a paradigm, psychoanalysis can add new perspectives to the study of social media addiction that open perspectives outside the rational. This study provides a gap in further research, the development of an algorithmic model of each social media that allows people to be addicted to social media. Conflicts caused by addiction to social media generally result in conflict between individuals and other people, such as boyfriends, friends, and parents. Further research is also expected to examine conflicts over relations with the government at regional, regional, city, provincial, state and global scales. By strengthening the study of indicators of social media addiction and the conflicts that accompany it, it is hoped that a good and smart society will become a good and smart society within the framework of digital citizenship and its applicability to society.

\section{REFERENCES}

[1] R. Joiner, J. Gavin, M. Brosnan, J. Cromby, H. Gregory, J. Guiller, P. Maras, A. Moon, "Comparing first and second generation digital natives' Internet use, Internet anxiety, and Internet identification," Cyberpsychology, Behavior, and Social Networking, vol. 16, no. 7, pp. 549-552, 2013.

[2] A. E. Cowey, H. W. W. Potts, "What can we learn from second generation digital natives? A qualitative study of undergraduates' views of digital health at one London university," Digital Health, vol. 4, pp. 1-13, 2018.

[3] A. Dingli, D. Seychell, The new digital natives: Cutting the chord. Heidelberg: Springer, 2015.

[4] Matang, Samsuri, "How is the use of social media in the student activist," Proceedings of the Annual Civic Education Conference (ACEC 2018), vol. 1, no. 1, pp. 72-75, 2018.

[5] R. Alnjadat, M. M. Hmaidi, T. E. Samha, M. M. Kilani, A. M. Hasswan, "Gender variations in social media usage and academic performance among the students of University of Sharjah," Journal of Taibah University Medical Sciences, vol. 14, no. 4, pp. 390-394, 2019.

[6] I. Acun, "The Relationship among University Students' Trust, Self-Esteem, Satisfaction with Life and Social Media Use," International Journal of Instruction, vol. 13, no. 1, pp. 35-52, 2020.

[7] F. Alshare, A. M. Alkhawaldeh, B. M. Eneizan, "Social Media Website's Impact on Moral and Social Behavior of the Students of University," International journal of academic research in business and social sciences, vol. 9, no. 3, pp. 169-182, 2019.

[8] S. A. Rahman, A. Al Marzouqi, S. Variyath, S. Rahman, M. Rabbani, S. I. Ahamed, "Effects of Social Media Use on Health and Academic Performance Among Students at the University of Sharjah," In 2020 IEEE 44th Annual Computers, Software, and Applications Conference (COMPSAC), pp. 711-716, IEEE, 2020.

[9] K. Kircaburun, S. Alhabash, Ş. B. Tosuntaş, M. D. Griffiths, "Uses and gratifications of problematic social media use among university students: A simultaneous examination of the Big Five of personality traits, social media platforms, and social media use motives," International Journal of Mental Health and Addiction, vol. 18, no. 3, pp. 525-547, 2020.

[10] D. R. Indah, "The Indirect Speech Acts of College and University Students' Meant Intentions in Social Media Communication," In Eleventh Conference on Applied Linguistics (CONAPLIN 2018), pp. 149-153. 2019.

[11] S. Solazzo, P. Hoffman, M. Chisolm, "Social media," In Textbook of cultural psychiatry, D. Bhugra and K. Bhui, Eds. Cambridge: Cambridge University Press, 2018, pp. 85-92.

[12] D. K. Ahmad, D. K. S. Sheikh, "Social media and youth participatory politics: A study of university students," South Asian Studies, vol. 28, no. 2, pp.353-360, 2020.

[13] F. L. Lee, M. Chan, H. T. Chen, "Social Media and Protest Attitudes During Movement Abeyance: A Study of Hong Kong University Students," International Journal of 
Communication, vol. 14, no. 20, pp. 4932-4951, 2020.

[14] J. B. Awotunde, R. O. Ogundokun, F. E. Ayo, G. J. Ajamu, E. A. Adeniyi, E. O. Ogundokun, "Social media acceptance and use among university students for learning purpose using UTAUT model," In International Conference on Information Systems Architecture and Technology, vol. 1050, pp. 91-102, 2019.

[15] V. J. Owan, I. A. Robert, "Analysis of the utilization of social media platforms and university students' attitudes towards academic activities in Cross River State, Nigeria," Prestige Journal of Education, vol. 2, no. 1, pp. 1-13, 2019.

[16] T. Pratchett, G. Young, C. Brooks, L. Jeskins, H. Monagle, Practical Tips for Developing Your Staff. London, UK: Facet Publishing, 2016.

[17] A. Błachnio, A. Przepiorka, E. Senol-Durak, M. Durak, L. Sherstyuk, "The role of personality traits in Facebook and Internet addictions: A study on Polish, Turkish, and Ukrainian samples," Computers in Human Behavior, vol. 68, pp. 269-275, 2017.

[18] R. Haand, Z. Shuwang, "The relationship between social media addiction and depression: a quantitative study among university students in Khost, Afghanistan," International Journal of Adolescence and Youth, vol. 25, no. 1, 780-786, 2020.

[19] M. Lyvers, S. S. Narayanan, F. A. Thorberg, "Disordered social media use and risky drinking in young adults: Differential associations with addiction-linked traits," Australian Journal of Psychology, vol. 71, no. 3, pp. 223-231, 2020.

[20] Ş. B. Tosuntaş, E. Karadağ, E. Emirtekin, K. Kircaburun, M. D. Griffiths, "Sofalizing and its relationship with social media addiction and psychosocial factors: A new phenomenon among emerging adults," The Social Science Journal, pp. $1-13,2020$.

[21] I. Abbasi, M. Drouin, "Neuroticism and facebook addiction: How social media can affect mood?," The American Journal of Family Therapy, vol. 47, no. 4, pp. 199-215, 2019.

[22] N. Bloemen, D. D. Coninck, "Social media and fear of missing out in adolescents: The role of family characteristics," Social Media + Society, vol. 6, no. 4, pp. 1-11, 2020.

[23] F. Reer, W. Y. Tang, T. Quandt, "Psychosocial well-being and social media engagement: The mediating roles of social comparison orientation and fear of missing out," New Media \& Society, 21(7), 1486-1505, 2019.

[24] L.-Y. Leong, T.-S. Hew, K.-B. Ooi, V.-H. Lee, J.-J. Hew, "A hybrid SEM-neural network analysis of social media addiction," Expert
Systems with Applications, vol. 133, pp. 296316, 2019.

[25] M. Karimy, F. Parvizi, M. R. Rouhani, M. D. Griffiths, B. Armoon, F. L. Moghaddam, "The association between internet addiction, sleep quality, and health-related quality of life among Iranian medical students," Journal of Addictive Diseases, vol. 38, no. 3, pp. 317-325, 2020.

[26] A. M. A. Nasirudeen, L. Lee Chin Adeline, K. Wat Neo Josephine, L. Lay Seng, L. Wenjie, "Impact of social media usage on daytime sleepiness: A study in a sample of tertiary students in Singapore," Digital Health, vol. 3, pp. 1-9, 2017.

[27] K. R. Swain, A. K. Pati, "Use of social networking sites (SNSs) and its repercussions on sleep quality, psychosocial behavior, academic performance and circadian rhythm of humans - a brief review," Biological Rhythm Research, pp. 1-40, 2019.

[28] D. E. Vlad, Concepts of quality connected to social media and emotions," Wiesbaden, Germany: Springer Gabler, 2020.

[29] A. E. Ouirdi, J. Segers, E. Hendrickx, "Social media conceptualization and taxonomy a lasswellian framework," Journal of Creative Communications, vol. 9, no. 2, pp. 107-126, 2014.

[30] D. R. Neal, Social media for academics: a practical guide. Oxford: Chandos Publishing, 2012.

[31] A. Gonçalves, Social Media Analytics Strategy: Using Data to Optimize Business Performance, Las Vegas, Nevada, USA: Apress, 2017.

[32] K.E. Anderson, "Getting acquainted with social networks and apps: Instagram's instant appeal", Library Hi Tech News, Vol. 33 No. 3, pp. 11-15, 2016.

[33] J. Lee, I. B. Hong, "Predicting positive user responses to social media advertising: The roles of emotional appeal, informativeness, and creativity," International Journal of Information Management, vol. 36, no. 3, pp. 360-373, 2016.

[34] O. Turel, D. Brevers, A. Bechara, "Time distortion when users at-risk for social media addiction engage in non-social media tasks," Journal of psychiatric research, vol. 97, pp. 8488, 2018.

[35] J. Balakrishnan, M. D. Griffiths, "Social media addiction: What is the role of content in YouTube?," Journal of behavioral addictions, vol. 6, no. 3, pp. 364-377, 2017.

[36] A. Kirik, A. Arslan, A. Çetinkaya, G. Ü. L. Mehmet, "A quantitative research on the level of social media addiction among young people in Turkey," International Journal of Sport Culture and Science, vol. 3, no. 3, 108-122, 2015. 
[37] N. S. Hawi, M. Samaha, "The relations among social media addiction, self-esteem, and life satisfaction in university students," Social Science Computer Review, vol . 35, no. 5, pp. 576-586, 2017.

[38] A. C. Nakaya, Internet and social media addiction. San Diego, CA: ReferencePoint Press, Inc, 2015.

[39] A. Tutgun-Ünal, L. Deniz, "Development of the social media addiction scale," AJIT-e: Bilişim Teknolojileri Online Dergisi, vol. 6, no. 21, pp. 51-70, 2015.

[40] K. Weixel-Dixon, Interpersonal conflict: An Existential Psychotherapeutic and Practical Model, New York: Routledge, 2017.

[41] J. L. Hocker, W. W. Wilmot, Interpersonal Conflict 10th Edition. New York, NY: McGrawHill, 2018.

[42] B. Van Niekerk, M. Maharaj, "Social media and information conflict," International Journal of Communication, vol. 7, no. 23, pp. 1162-1184, 2013.

[43] C. Elsaesser, D. U. Patton, E. Weinstein, J. Santiago, A. Clarke, R. Eschmann, "Small becomes big, fast: Adolescent perceptions of how social media features escalate online conflict to offline violence," Children and youth services review, vol. 122, 105898, 2021.

[44] I. Käihkö, "Conflict chatnography: Instant messaging apps, social media and conflict ethnography in Ukraine," Ethnography, vol. 21, no. 1, pp. 71-91, 2020.

[45] R. Shah, N. Chauhan, A. K. Gupta, M. S. Sen, "Adolescent-parent conflict in the age of social media: Case reports from India," Asian Journal of Psychiatry, Vol. 23, pp. 24-26, 2016.

[46] M. Makhortykh, M. Sydorova, "Social media and visual framing of the conflict in Eastern Ukraine," Media, War \& Conflict, vo. 10, no.3, pp. 359-381, 2017.

[47] S. Brooks, P. Longstreet, C. Califf, "Social media induced technostress and its impact on Internet addiction: A distraction-conflict theory perspective," AIS Transactions on HumanComputer Interaction, vol. 9, no.2, pp. 99-122, 2017.

[48] T. Zeitzoff, "How Social Media Is Changing Conflict," Journal of Conflict Resolution, vol. 61, no. 9, pp. 1970-1991, 2017.

[49] S. E. Efron, R. Ravid, Writing the literature review: A Practical Guide, New York: The Guilford Press, 2019.

[50] D. Harris, Literature review and research design: A guide to effective research practice, London: Routledge, 2020.

[51] R. Maijala, S. Eloranta, T. Reunanen, T. S. "Successful implementation of lean as a managerial principle in health care: a conceptual analysis from systematic literature review," International journal of technology assessment in health care, vol. 34, no. 2, pp. 134-146, 2018.

[52] L. Monacis, V. De Palo, M. D. Griffiths, M. Sinatra, "Social networking addiction, attachment style, and validation of the Italian version of the Bergen Social Media Addiction Scale," Journal of Behavioral Addictions, vol. 6, no.2, pp. 178186, 2017.

[53] N. Hawi, M. Samaha, "Identifying commonalities and differences in personality characteristics of Internet and social media addiction profiles: traits, self-esteem, and self-construal," Behaviour \& Information Technology, vol. 38, no. 2, pp. 110-119, 2018.

[54] C. Longobardi, M. Settanni, M. A. Fabris, D. Marengo, "Follow or be followed: Exploring the links between Instagram popularity, social media addiction, cyber victimization, and subjective happiness in Italian adolescents," Children and Youth Services Review, vol. 113, 104955, 2020.

[55] M. Dalvi-Esfahani, A. Niknafs, D. J. Kuss, M. Nilashi, S. Afrough, "Social Media Addiction: Applying the DEMATEL Approach," Telematics and Informatics, 43, 101250, 2019.

[56] K. S. Young, Social Media Addiction: Assessment and Treatment, http://www.psychiatryonline.it/node/6078, 2020.

[57] J. Johanssen, Psychoanalysis and digital culture: Audiences, social media, and big data, New York, NY: Taylor \& Francis, 2019.

[58] A. R. Nelakurthi, J. He, Social media analytics for user behavior modeling: A task heterogeneity perspective. New York: CRC Press, 2020. 